\begin{tabular}{|c|c|}
\hline Title & $\begin{array}{l}\text { The spatial distribution of product desorption in the oxidation of carbon monoxide on platinum }(110)(1 \times 2) \\
\text { reconstructed surfaces }\end{array}$ \\
\hline Author(s) & Matsushima, Tatsuo \\
\hline Citation & $\begin{array}{l}\text { The Journal of Chemical Physics, 93(2), } 14641471 \\
\text { https://doi.org/10.1063/1.459156 }\end{array}$ \\
\hline Issue Date & 1990-07-15 \\
\hline Doc URL & http:/hdl.handle.net/2115/13166 \\
\hline Rights & Copyright @ 1990 A merican Institute of Physics \\
\hline Type & article \\
\hline File Information & JCP1990Pt110-1x2.pdf \\
\hline
\end{tabular}

Instructions for use 


\title{
The spatial distribution of product desorption in the oxidation of carbon monoxide on platinum $(110)(1 \times 2)$ reconstructed surfaces
}

\author{
Tatsuo Matsushima \\ Institute for Molecular Science, Myodaiji, Okazaki 444, Japan
}

(Received 19 March 1990; accepted 5 April 1990)

\begin{abstract}
The spatial distribution of the desorption of carbon dioxide produced on platinum (110) $(1 \times 2)$ reconstructed surfaces was studied in the wide range of the reactant coverages by means of angle-resolved thermal desorption and low-energy electron diffraction. Heating the surface covered by oxygen atoms and carbon monoxide yields four peaks in the $\mathrm{CO}_{2}$ formation: $P_{1}$-around $400 \mathrm{~K}, P_{2^{-}}(300 \mathrm{~K}), P_{3^{-}}(250 \mathrm{~K})$, and $P_{4}-\mathrm{CO}_{2}$ peaks $(170 \mathrm{~K})$. The desorption of each $\mathrm{CO}_{2}$ indicated a sharp angular distribution collimated along the bulk surface normal in the [110] direction. On the other hand, the desorption of $P_{1}$-and $P_{2}-\mathrm{CO}_{2}$ produced at small $\mathrm{CO}$ coverages showed two-directional desorption collimated at either about +23 or -23 degrees off the bulk surface normal in the [001] direction. It indicates that the reactive desorption takes place on declining terraces of the reconstructed plane. The desorption of $P_{3}-$ and $P_{4}-\mathrm{CO}_{2}$, and also of $P_{2}-\mathrm{CO}_{2}$ produced at high initial $\mathrm{CO}$ coverages, showed a single peak in the angular distribution curve in the same direction, which was collimated along the bulk surface normal. This suggests that the reconstruction is at least partly lifted during heating procedures, and $\mathrm{CO}_{2}$ is formed on the nonreconstructed as well as the reconstructed plane. It was supported by low-energy electron diffraction observations.
\end{abstract}

\section{INTRODUCTION}

For several decades, the rate of elementary processes involved in surface reactions has been treated in surface chemical kinetics as a function of reactant coverages as well as surface temperature. The uniformity in the distribution of adsorbed reactants and also their reactivity is tacitly assumed in such treatments. However, the construction of phase diagrams of two-dimensional chemisorption systems provides ample evidence that adsorbed species are not necessarily uniformly distributed over the whole surface. ${ }^{1}$ In some cases, adspecies form separate domains. The sizes of the domains depend on the coverage and the surface temperature. The formation of domains will be accelerated in the coadsorption system, when the repulsive force is operative between coadspecies. ${ }^{2-4}$ In such cases, the reaction occurs predominantly between the domains, such as the $\mathrm{CO}$ oxidation on platinum metals. ${ }^{2-5}$

The reaction rate as well as the selectivity of the surface reactions is sensitive to the structure of the reaction site. ${ }^{6}$ This structure has been derived from various spectroscopies and diffraction methods. However, such information on the reaction site is indirect, since it is based on signals from nonreacting surface species. Here, we need a new approach to surface reaction dynamics sensitive to the structure of reaction sites. We have expected that the spatial distribution of the desorption flux of product molecules will open such dynamics in the first stage, because it depends on the arrangement of substrate atoms constructing the reaction site as well as the structure of the coadlayer around the site.,

In this paper, we will report the spatial distribution of the desorption of $\mathrm{CO}_{2}$ produced on $\mathrm{Pt}(110)(1 \times 2)$ reconstructed surfaces. The results indicate that the orientation of the reaction site is mostly preserved in the spatial distribution. Experimental studies including low-energy electron diffraction (LEED), ${ }^{8 a}$ ion scattering, ${ }^{9,10}$ field ion microscopy $^{11}$ and scanning tunneling microscopy (STM) ${ }^{12}$ favor the missing-row model for the reconstruction. In this model, the surface consists of close-packed atomic rows in the [110] direction, and three-atom-wide terraces of a (111) structure in the [001] direction. The recent analysis by LEED $^{8 \mathrm{~b}}$ and He scattering ${ }^{13}$ indicates large contractions in the first four layers. The resultant terraces decline at either about +30 or -30 degrees. This surface provides a model suitable for examining whether the desorption of molecules produced on declining reaction sites is collimated along the bulk surface normal or the terrace surface normal.

This subject was once studied for the desorption of hydrogen on a stepped $\mathrm{Cu}(310)$ surface, ${ }^{14}$ and also on $\mathrm{Ni}(997) .{ }^{15}$ No anisotropy was found in the desorption flux on the former surface, concluding that the repulsive potential lost the effect from the surface corrugation at the position of molecule formation. ${ }^{14}$ In the latter, the desorption occurred from step sites, which was collimated at about 25 degrees off the bulk surface normal. We have previously discussed the applicability of produced $\mathrm{CO}_{2}$ as a probe towards the structure of reaction sites, and less sensitivity of the hydrogen desorption. ${ }^{7}$

\section{EXPERIMENTAL}

The experimental apparatus and procedures were reported previously. ${ }^{16}$ The apparatus consisted of a reaction chamber [with low-energy electron diffraction Auger electron spectroscopy (LEED-AES) ], a collimator, and an analyzer chamber. The flux of $\mathrm{CO}_{2}$ molecules desorbing from the surface and passing through the collimator slits contributes mostly to the signal of the mass spectrometer in the analyzer chamber (angle-resolved spectra). The $\mathrm{CO}_{2}$ for- 
mation was simultaneously recorded with another mass spectrometer in the reaction chamber (angle-integrated spectra). Two platinum crystals in a disk-shaped slice (11 $\mathrm{mm}$ diameter $\times 0.9 \mathrm{~mm}$ thickness) were used. Either was set on a rotable axis perpendicular to the axis of the collimator, so as to be rotated either in the [110] or [001] direction. It could be cooled down to $100 \mathrm{~K}$ and heated resistively.

The sample crystal was cleaned by repeated $\mathrm{Ar}^{+}$bombardment in the temperature region of $300 \mathrm{~K}$ to $1000 \mathrm{~K}$ and heating in $5 \times 10^{-8}$ Torr oxygen around $800 \mathrm{~K}$. It was heated to $1400 \mathrm{~K}$ before each adsorption experiment. At this stage, a sharp $(1 \times 2)$ LEED pattern was observed. The spot intensity was monitored by a spot photometer with a photomultiplier tube. The temperature was monitored with a chromel-alumel thermocouple spot welded to the side of the crystal.

\section{RESULTS}

\section{A. Adsorption of carbon monoxide and oxygen}

Carbon monoxide adsorbs quickly on the $(1 \times 2)$ reconstructed surface around $110 \mathrm{~K}$. The initial sticking probability was estimated at close to unity from thermal desorption. CO forms a $c(8 \times 4)$ structure at saturation, in which the density has been reported to be $9.2 \times 10^{14} / \mathrm{cm}^{2}$ by nuclear microanalysis (NMA). ${ }^{10}$ The coverage used below, $\theta_{\mathrm{CO}}$, represents the peak area of thermal desorption relative to that at saturation described above. Heating this CO-covered surface above $300 \mathrm{~K}$ lifted the surface reconstruction. ${ }^{17}$ The reconstruction was restored around $500 \mathrm{~K}$ after the $\mathrm{CO}$ desorption, which peaked at $380 \mathrm{~K}$ and $480 \mathrm{~K}$ at high coverages. ${ }^{18}$

Oxygen adsorbs quickly and molecularly around $100 \mathrm{~K}$. The desorption and dissociation is complete below 250 K. ${ }^{19,20}$ The reconstruction was not removed by the adsorption of molecular oxygen as well as atomic form. ${ }^{21}$ The amount of oxygen adatoms produced with large exposures $\left(>1.5 \mathrm{~L} \mathrm{O}_{2}\right.$ ) above $250 \mathrm{~K}$ was very close to half of that produced by annealing the surface covered by molecular oxygen in large amounts to $250 \mathrm{~K}$. X-ray photoelectron spectroscopy (XPS) measurements by Freyer et al. ${ }^{21}$ have showed that the density in the former is $3.2 \times 10^{14}$ atoms $/ \mathrm{cm}^{2}$, and the latter $6.4 \times 10^{14}$ atoms $/ \mathrm{cm}^{2}$. In the following, the relative coverage $\theta_{0}$ [the ratio of the number of oxygen adatoms to that of top-most metal atoms for $\mathbf{P t}$ (110) $(1 \times 1)]$ is used to represent the density.

The oxygen adsorption at room temperature yielded half-order spots in the LEED screen, which were sharp in the $[1 \overline{1} 0]$ direction and streaky in the [001] direction. It seems to form a $c(2 \times 4)$ structure at $\theta_{0}=0.35$. The intensity was very weak, however, the pattern was clearly seen below $200 \mathrm{~K}$. The intensity was not enhanced by annealing the surface to $600 \mathrm{~K}$. This is quite different from the same structure on $\operatorname{Pd}(110){ }^{22}$

\section{B. $\mathrm{CO}$ adsorption on the oxygen-covered surface}

The adsorption of $\mathrm{CO}$ on the oxygen-covered surface was as rapid as that on the clean surface. The rate was not retarded by preadsorbed oxygen even at $\theta_{0}=0.70$, although the saturation level was reduced slightly. The adsorption was followed by monitoring the desorption of oxygen and carbon monoxide in the subsequent thermal desorption. The desorption of $\mathrm{CO}$ was not detected as long as that of oxygen was noticeable, i.e., oxygen was removed as $\mathrm{CO}_{2}$ when $\mathrm{CO}$ was present on the surface. Hence, the amount of oxygen and $\mathrm{CO}$ adsorbed was estimated from only the desorption of these species when the surface with a known amount of oxygen was exposed to $\mathrm{CO}$, since the reaction of $\mathrm{CO}$ with oxygen was very slow at $110 \mathrm{~K}$. The amount of oxygen desorbed as $\mathrm{O}_{2}$ decreased almost linearly against the $\mathrm{CO}$ exposure, independent of the initial oxygen coverage. The slope indicated the adsorption rate of $\mathrm{CO}$, which removed oxygen as $\mathrm{CO}_{2}$. It was equal to the adsorption rate of $\mathrm{CO}$ on the clean surface.

\section{C. $\mathrm{CO}_{2}$ formation}

A clean and well-ordered $\mathrm{Pt}(110)(1 \times 2)$ reconstructed surface was exposed to ${ }^{18} \mathrm{O}_{2}$ at $250 \mathrm{~K}$, and further exposed to $\mathrm{C}^{16} \mathrm{O}$ at $110 \mathrm{~K}$. The surface was heated at a rate of $16 \mathrm{~K} / \mathrm{s}$, while the amount of $\mathrm{C}^{16} \mathrm{O}^{18} \mathrm{O}$ produced was monitored in both angle-resolved and angle-integrated form. ${ }^{18} \mathrm{O}$ will be simply referred to as $\mathrm{O}$ in the following, since only $\mathrm{C}^{16} \mathrm{O}^{18} \mathrm{O}$ was produced during the above procedures.

The formation of $\mathrm{CO}_{2}$ peaked around $400 \mathrm{~K}\left(P_{1}-\mathrm{CO}_{2}\right)$ when the total coverage was small. ${ }^{23}$ With increasing $\mathrm{CO}$ exposures, the formation extended to lower temperatures, yielding $P_{2}-\mathrm{CO}_{2}$ around $300 \mathrm{~K}, P_{3}-\mathrm{CO}_{2}(250 \mathrm{~K})$, and $P_{4^{-}}$ $\mathrm{CO}_{2}(170 \mathrm{~K}) . P_{2}-\mathrm{CO}_{2}$ first appeared at small $\mathrm{CO}$ coverages when the initial oxygen coverage was high. Such appearance of $P_{2}-\mathrm{CO}_{2}$ was already observed on Pd (110). ${ }^{7}$ The formation of $P_{1}-\mathrm{CO}_{2}$ was observed only when the total coverage was small. Typical $\mathrm{CO}_{2}$ formation spectra generated from $\theta_{0}=0.35$ in angle-integrated form are reproduced in Fig. 1 (a). Above $\theta_{\mathrm{CO}}=0.3$ and below $\theta_{0}=0.35$, the formation of $P_{1}-\mathrm{CO}_{2}$ was rapidly suppressed and the peaks of $P_{3}$ - and $P_{4}-\mathrm{CO}_{2}$ appeared. The separation of the peaks was poor when the reaction was generated from $\theta_{0}=0.70 . P_{3}-\mathrm{CO}_{2}$ appeared as a shoulder on the $P_{2}-\mathrm{CO}_{2}$ peak, and the $P_{4}-\mathrm{CO}_{2}$ peak was not separated well from the combined peak of $P_{2}-$ and $P_{3}-\mathrm{CO}_{2}$. Therefore; the spectra generated from such high oxygen coverages will not be discussed in detail in the following.

\section{Angular distribution in the [1]10] direction}

The desorption flux of produced $\mathrm{CO}_{2}$ showed anisotropic angular distribution dependent upon the crystallographic orientation of the surface. Typical angle-resolved $\mathrm{CO}_{2}$ spectra observed at the surface normal are summarized in Fig. 1(b). It should be noticed that the ratio of the $\mathrm{CO}_{2}$ peak height in angle-resolved form to that in angle-integrated form increased only slightly, i.e., in the order of $P_{1^{-}}<P_{2^{-}}$ $<P_{3^{-}}<P_{4}-\mathrm{CO}_{2}$. In the angle-resolved reactive $\mathrm{CO}_{2}$ desorption experiments reported so $\mathrm{far}^{3,7,24}$ the ratio increases sharply with increasing reactant coverages. In other words, the angular distribution becomes sharp as the density of reactants increases. This scarce increase in the present ratio suggests that the desorption is not necessarily collimated along the surface normal. We determined the angular distri- 


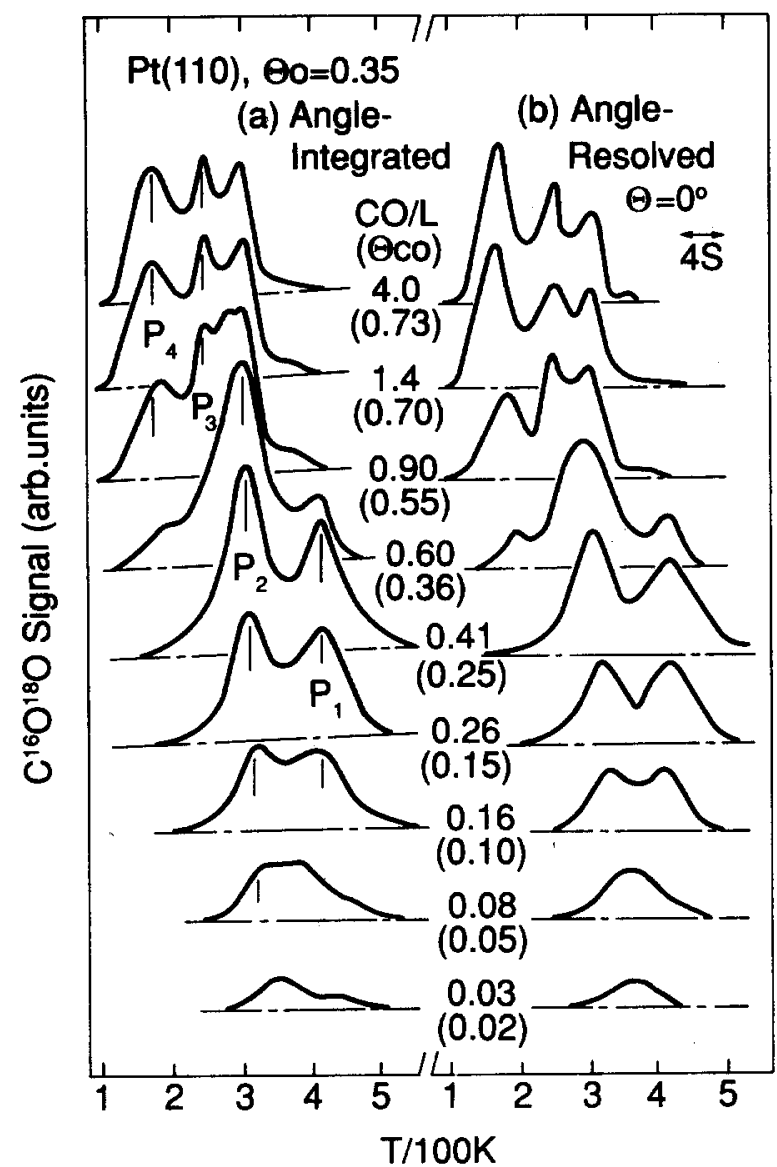

FIG. 1. $\mathrm{CO}_{2}$ formation spectra generated at a high oxygen coverage and various $\mathrm{CO}$ exposures. The spectra were simultaneously recorded in both (a) angle-integrated and (b) angle-resolved form. The surface was saturated by ${ }^{18} \mathrm{O}$ at $250 \mathrm{~K}$, exposed to ${ }^{12} \mathrm{C}^{16} \mathrm{O}$ at $110 \mathrm{~K}$ and then heated at a rate of $16 \mathrm{~K} / \mathrm{s}$. The values in parentheses indicate the $\mathrm{CO}$ coverage estimated in the way described in the text.

bution of all $\mathrm{CO}_{2}$ desorption at their peak temperatures in both [001] and [110] directions.

Typical desorption spectra observed at various desorption angles in the [110] direction (in the azimuth $\phi=90^{\circ}$ ) are reproduced in Fig. 2. The upper panel shows the desorption of $\mathrm{CO}_{2}$ and $\mathrm{CO}$ in angle-integrated form. $\mathrm{CO}$ is desorbed at temperatures higher than those for the $\mathrm{CO}_{2}$ formation. No oxygen was desorbed under these conditions. The signal of $\mathrm{CO}_{2}$ should not be compared with that of $\mathrm{CO}$, since the pumping rate of the reaction chamber was very high for $\mathrm{CO}_{2}$. The lower panel reproduces typical angle-resolved spectra. The signal of $P_{4}-\mathrm{CO}_{2}$ was slightly enhanced in the normal direction. With the increasing desorption angle, it decreased slightly more rapidly than the others. In fact, the angular distribution in this direction becomes slightly sharp in the order of $P_{1^{-}}<P_{2^{-}}<P_{3^{-}}<P_{4}-\mathrm{CO}_{2}$.

The angular distribution along the surface trough $\left(\phi=90^{\circ}\right)$ is characteristic of a collimation along the bulk surface normal. The distribution of $P_{1}-\mathrm{CO}_{2}$ desorption in the [110] direction is shown in Fig. 3. The signal varied as $(\cos \theta)^{6 \pm 1}$, independent of the initial coverages of oxygen and $\mathrm{CO}$. The open circles in the figure show the results obtained in the $\mathrm{CO}_{2}$ formation generated at high coverages. In

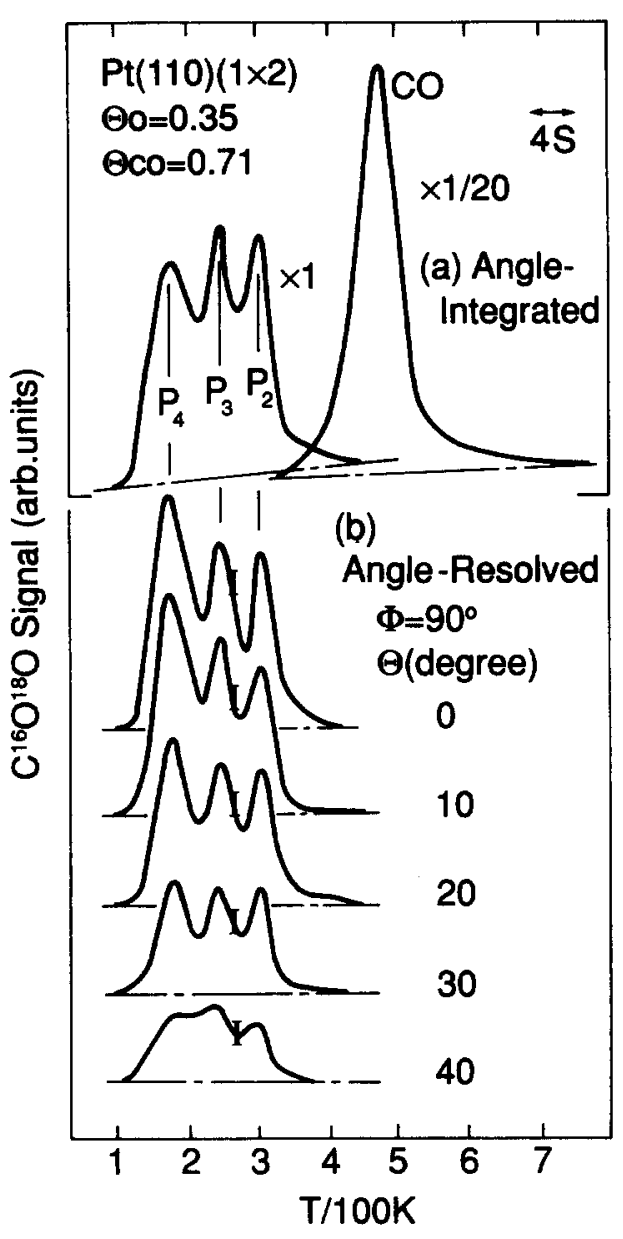

FIG. 2. (a) Spectra of $\mathrm{CO}_{2}$ formation and $\mathrm{CO}$ desorption in angle-integrated form at a high $\mathrm{CO}$ coverage (b) Angle-resolved $\mathrm{CO}_{2}$ spectra observed at various desorption angles in the $[1 \overline{1} 0]$ direction. The vertical bars indicate the noise level.

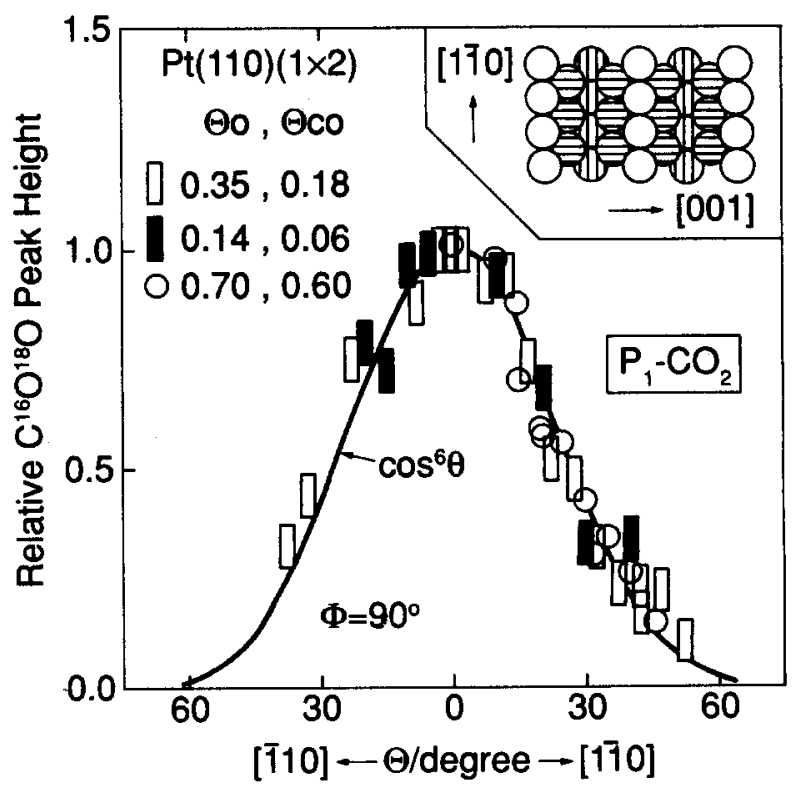

FIG. 3. Angular distribution of the $P_{1}-\mathrm{CO}_{2}$ desorption flux in the [110] direction. The inserted figure shows a top view of the missing-row structure. The coverages shown in the figure are the initial values. 
this case, the surface was first exposed to $1.8 \mathrm{~L} \mathrm{O}_{2}$ at $110 \mathrm{~K}$ and annealed to $270 \mathrm{~K}$. It was further exposed to $1.0 \mathrm{~L} \mathrm{CO}$ at $110 \mathrm{~K}$ and heated. Even in this case, the $\mathrm{CO}$ and oxygen coverages were reduced very much at temperatures where $P_{1}-\mathrm{CO}_{2}$ was formed. Hence, no effect of a high initial oxygen coverage was found in the angular distribution of $P_{1}-\mathrm{CO}_{2}$. The desorption of $P_{2}-\mathrm{CO}_{2}$ showed $(\cos \theta)^{7 \pm 1}$ dependence in the formation from $\theta_{0}=0.14 \sim 0.70$ and $\theta_{\mathrm{CO}}=0.24 \sim 0.71$. The desorption of $P_{3}-\mathrm{CO}_{2}$ yielded a similar dependence in the generation from $\theta_{0}=0.14 \sim 0.70$ and $\theta_{\mathrm{CO}}=0.71 \sim 0.73$. On the other hand, the desorption of $P_{4}=\mathrm{CO}_{2}$ showed a slightly sharper distribution of $(\cos \theta)^{8 \pm 1}$ in the formation from $\theta_{0}=0.14 \sim 0.70$ and $\theta_{\text {Co }}=0.55 \sim 0.73$.

\section{E. Angular distribution in the [001] direction}

The distribution perpendicular to the surface trough $\left(\phi=0^{\circ}\right)$ is quite different from that parallel to the trough. The results for $P_{2}-\mathrm{CO}_{2}$ are shown in Fig. 4. The $\mathrm{CO}_{2}$ formation was generated from $\theta_{0}=0.14$ and $\theta_{\mathrm{CO}}=0.36$, where only $P_{2}-\mathrm{CO}_{2}$ was produced. The distribution is characteristic of two-directional desorption. The solid curves were drawn by being normalized to the signal at the bulk surface normal and fitted to the data by assuming the same power series of $\cos \theta$. This fitting procedure yielded $\cos (\theta \pm 23)^{13 \pm 2}$ dependence. The desorption peaked at either +23 or -23 degrees off bulk surface normal. We examined this interesting desorption on two different crystals. The results were

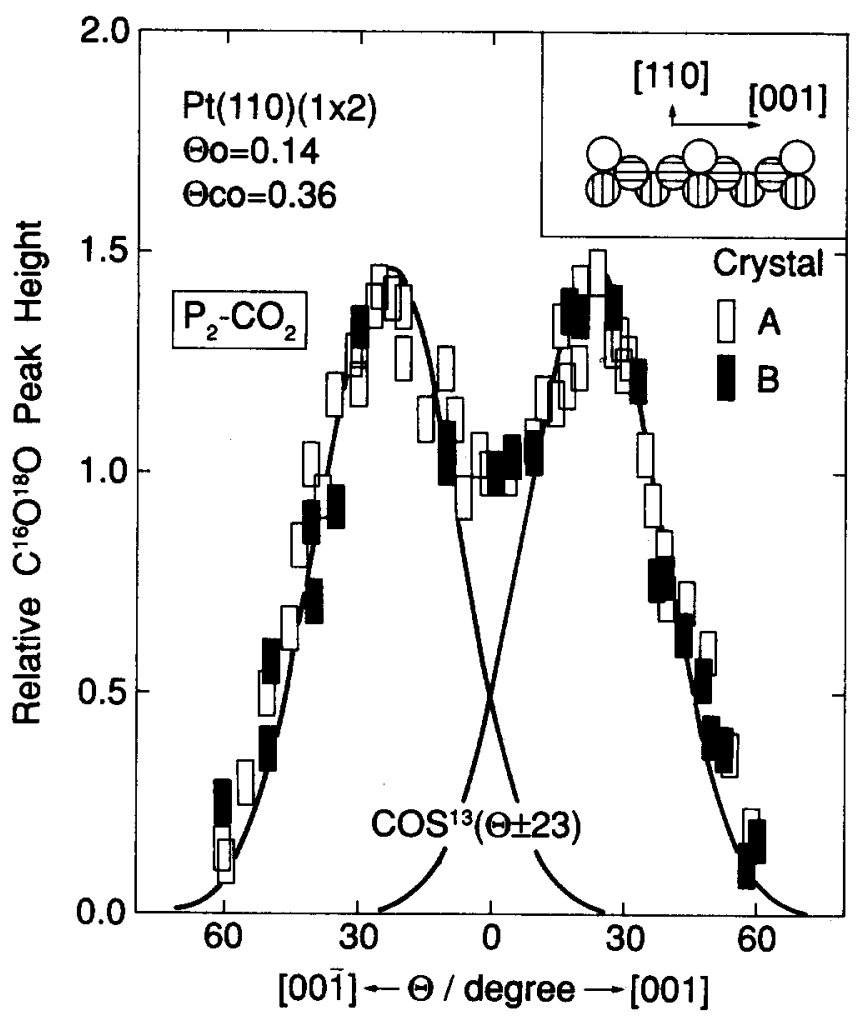

FIG. 4. Angular distribution of the desorption flux of $P_{2}-\mathrm{CO}_{2}$ produced at a small $\mathrm{CO}$ coverage in the [001] direction. A side view of the missing-row structure is drawn in the inserted figure. Results obtained on different samples were summarized. well reproduced on both crystals as shown in the figure. This two-directional desorption was confirmed for the $P_{2}-\mathrm{CO}_{2}$ formation started from $\theta_{0}=0.14 \sim 0.70$ and $\theta_{\mathrm{co}}<0.40$.

The angular distribution of $P_{1}=\mathrm{CO}_{2}$ desorption is shown in Fig. 5. Data in this case were rather scattered because of small signals. These data were well described by a similar two-directional desorption collimated along the axis at $\theta= \pm 21$ degrees, in which each component had $(\cos \theta)^{13 \pm 2}$ dependence.

In contrast, no two-directional desorption was found in the $\mathrm{CO}_{2}$ formation started from $\theta_{\mathrm{co}}>0.5$. The distribution was rather broad and in a single peak collimated along the bulk surface normal. The results for $P_{2}-\mathrm{CO}_{2}$ are shown in Fig. 6. It varied as $(\cos \theta) .{ }^{3-4}$ The broad distribution seems to consist of three components, as described in the discussion section.

The angular distribution of $P_{3}$ - and $P_{4}-\mathrm{CO}_{2}$ was similar to this $P_{2}-\mathrm{CO}_{2}$. The former showed $(\cos \theta)^{3-5}$ dependence and the latter $(\cos \theta){ }^{5 \pm 1}$ The results of $P_{4}-\mathrm{CO}_{2}$ are shown in Fig. 7. No two-directional desorption was found for these $\mathrm{CO}_{2}$.

\section{F. LEED data}

The results summarized in the former section suggest that the reconstructed structure is kept during the $\mathrm{CO}_{2}$ formation started from small CO coverages. However, the reconstruction seems to be at least partly lifted at the early part

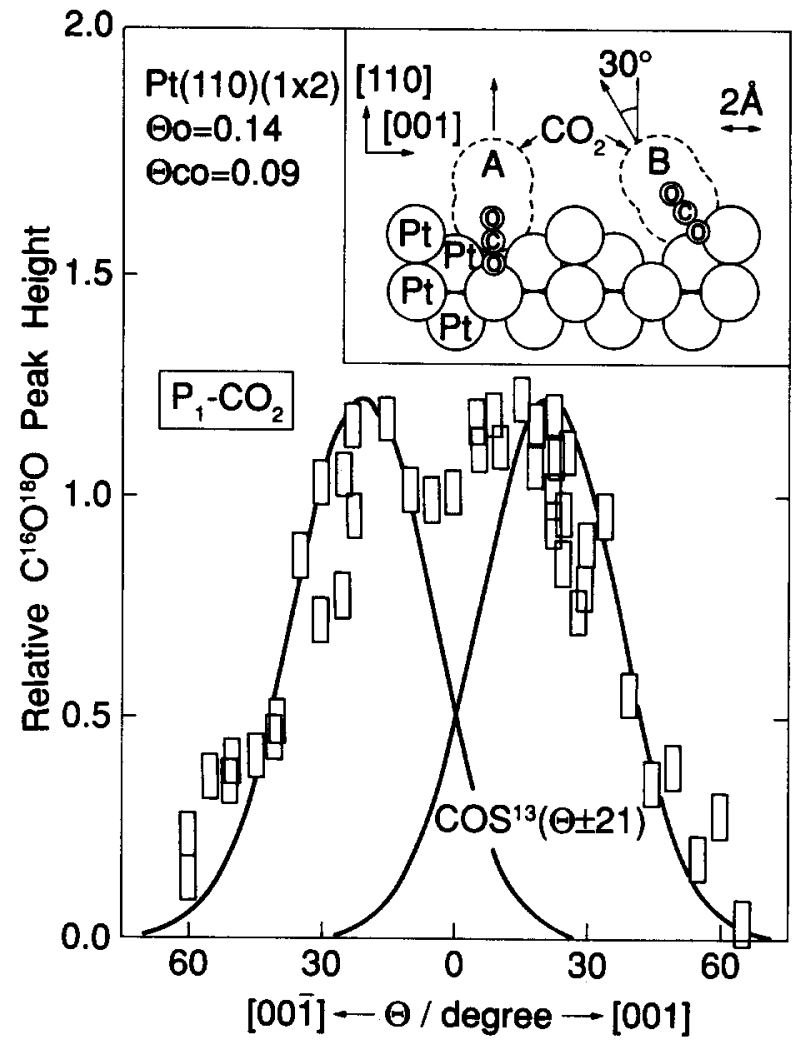

FIG. 5. Angular distribution of the $P_{1}-\mathrm{CO}_{2}$ desorption in the $[001]$ direction. The inserted figure shows sketches of sections of two possible reaction sites for $\mathrm{CO}_{2}$ formation: (A) a long bridge site in the valley, and (B) a threefold hollow site on the terrace. The dotted curves representing the size of physisorbed $\mathrm{CO}_{2}$ were drawn by using van der Waals' radii. 


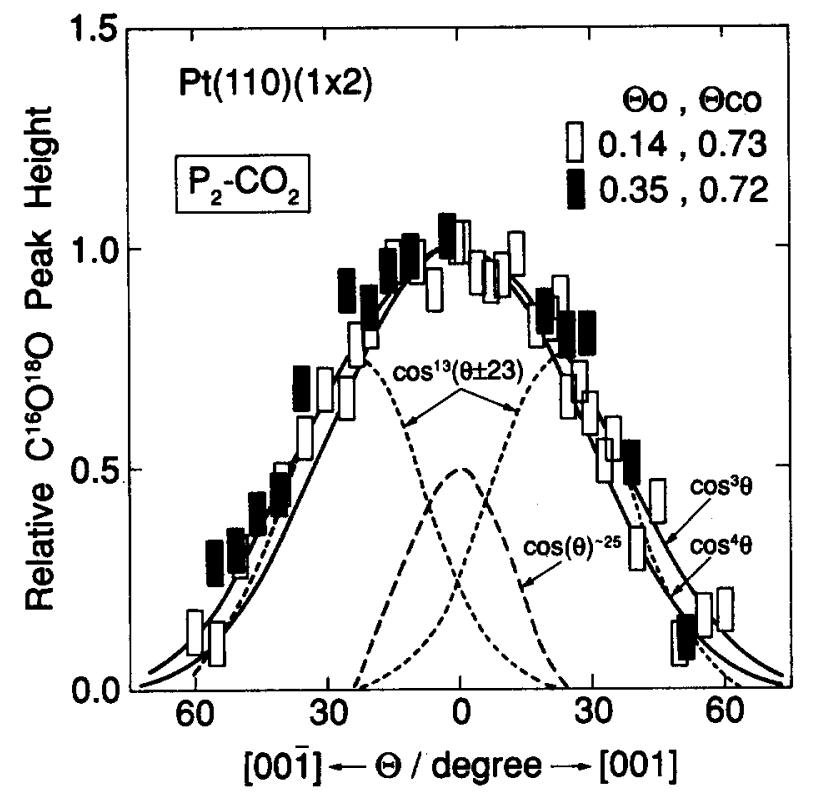

FIG. 6. Angular distribution in the [001] direction of the desorption flux of $P_{2}-\mathrm{CO}_{2}$ produced in the heating started from high $\mathrm{CO}$ coverages. The dotted curves were drawn by assuming the distribution of $(\cos \theta \pm 23)^{13}$ and fitting with the data at $\theta>23$ degrees. The dashed curve is the difference between the data and the former components.

of thermal desorption at high CO coverages. These were supported by the following LEED observations. The intensities of the diffraction spots, the half-order spot at $(0,3 / 2)$ and the integral order spot at $(0,2 / 2)$, were monitored during sequential heating procedures of the coadlayer. The former was monitored at an accelerating voltage $E_{0}=46 \mathrm{~V}$ and the latter at $E_{0}=64 \mathrm{~V}$. Typical results in the heating started from a high $\mathrm{CO}$ coverage were shown in Fig. 8. No background intensity was subtracted.

The intensity of the half-order spot decreased sharply after the $\mathrm{CO}$ exposure. This is probably due to the scattering

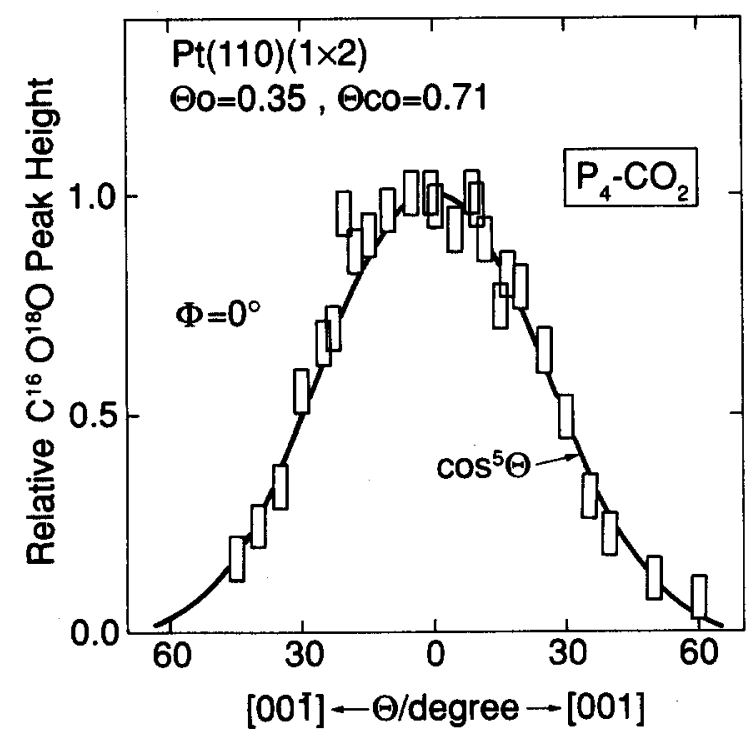

FIG. 7. Angular distribution of the $P_{4}-\mathrm{CO}_{2}$ desorption in the [001] direction.

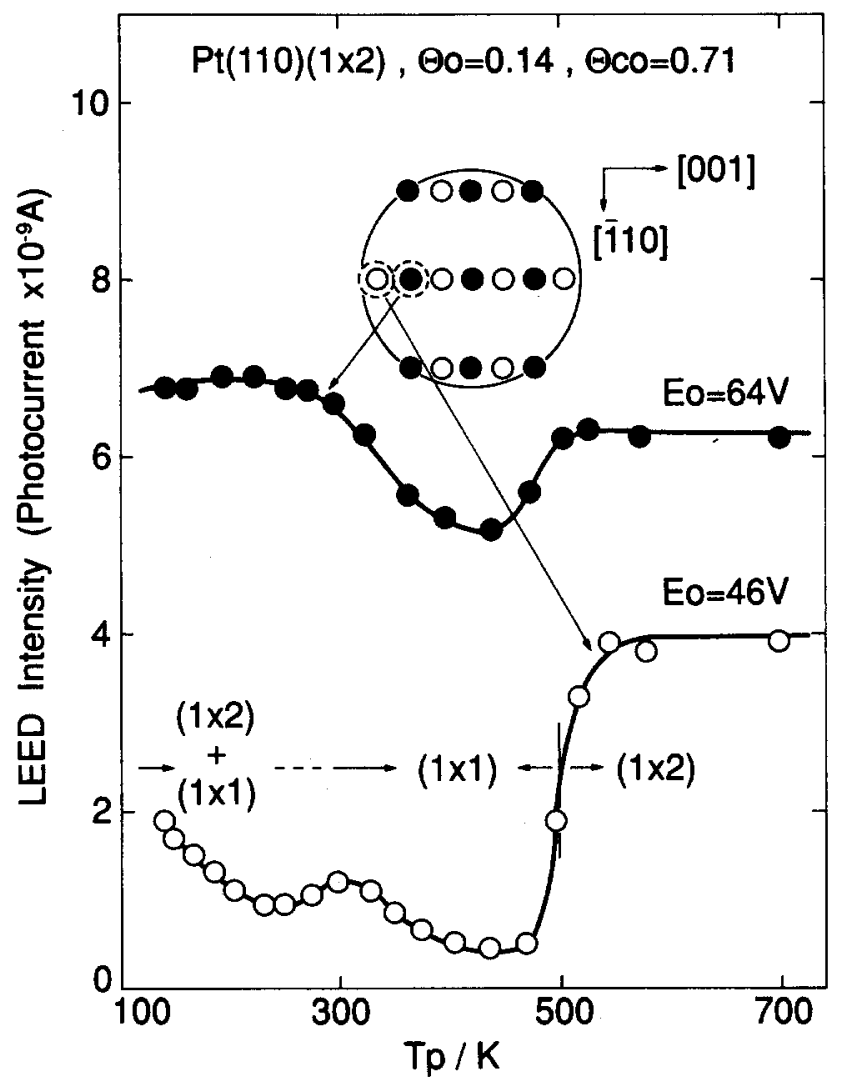

FIG. 8. Variation of the LEED intensity of the spots at $(0,2 / 2)$ and $(0$, $3 / 2$ ). The surface covered by oxygen at $250 \mathrm{~K}$ was exposed to $1.5 \mathrm{~L} \mathrm{CO}$ at $110 \mathrm{~K}$ and heated to $T_{p}$ at a rate of $3 \mathrm{~K} / \mathrm{s}$. The intensity was measured at 200 $\mathbf{K}$ by a spot photometer. The open circles in the inserted figure represent spots due to the $(1 \times 2)$ structure and closed circles integral order spots. $E_{o}$ is the accelerating voltage.

of electrons by $\mathrm{CO}$ molecules and not due to the removal of reconstruction, since the removal is very slow around $110 \mathrm{~K} \cdot{ }^{17}$ The intensity decreased further with an increase in the annealing temperature $T_{p}$ with a small maximum around $300 \mathrm{~K}$. This decrease was due to the removal of reconstruction. The mechanism of this maximum is not clear at present. The sharp increase around $500 \mathrm{~K}$ is due to the restoration of reconstruction after the $\mathrm{CO}$ desorption. ${ }^{17,18}$

On the other hand, the intensity of the integral order spot remained constant to about $300 \mathrm{~K}$. It showed a minimum around $420 \mathrm{~K}$ and recovered to the initial level on the clean $(1 \times 2)$ surface above $500 \mathrm{~K}$. Generally the $(1 \times 1)$ structure was predominant between $350 \mathrm{~K}$ and $470 \mathrm{~K}$ at high initial CO coverages. Below $300 \mathrm{~K}$, both $(1 \times 2)$ and $(1 \times 1)$ structures coexisted. The minimum around $450 \mathrm{~K}$ for $\theta_{0}=0.14$ decreased almost linearly with increasing CO coverages and reached very small values around $\theta_{\mathrm{co}}=0.60$. In other words, for this initial CO coverage, the removal of the reconstruction was almost complete around $450 \mathrm{~K}$. The transformation to $(1 \times 1)$ structure seemed to be slow below $300 \mathrm{~K}$ even at $\theta_{\mathrm{Co}}>0.60$, irrespective of the oxygen coverage. Below this coverage, the reconstruction remained partly around $450 \mathrm{~K}$. No decrease was found in the intensity of the half-order spot between $150 \mathrm{~K}$ and $450 \mathrm{~K}$ when $\theta_{\mathrm{co}}<0.36$. No transformation occurred at small $\mathrm{CO}$ coverages. 


\section{DISCUSSION}

\section{A. Removal of reconstruction}

The following points are well known for the transformation between $(1 \times 1)$ and $(1 \times 2)$ structures on $\operatorname{Pt}(110)$ surfaces. First, the metastable clean $(1 \times 1)$ phase converts to the stable $(1 \times 2)$ structure above $280 \mathrm{~K} \cdot .^{12,25-28}$ Second, the adsorption of CO causes a removal of the $(1 \times 2)$ reconstruction above room temperature. ${ }^{12,25,29-31}$ Third, the removal is slow at lower temperatures because of the restricted surface diffusivity of platinum atoms. ${ }^{12,17}$ Fourth, adsorbed $\mathrm{CO}$ can stabilize the $(1 \times 1)$ structure. The transformation to $(1 \times 2)$ structure during the $\mathrm{CO}$ desorption begins when the CO coverage drops below the critical value $\left(\theta_{\mathrm{CO}}=0.5\right)$ for keeping the $(1 \times 1)$ phase stable. ${ }^{13}$ Finally,the adsorption of oxygen does not affect the Pt surface structure, i.e., it does not induce reconstruction of the $(1 \times 1)$ nor destabilize the reconstructed $(1 \times 2)$ structure. ${ }^{21,25,32}$

A critical $\mathrm{CO}$ exposure of about 1 Langmuir has been found for starting the transition of the stable $(1 \times 2)$ structure into the $(1 \times 1)$ phase by using STM. ${ }^{12}$ The coverage achieved by this exposure was not clear; however, $\theta_{\mathrm{CO}} \approx 0.4$ was estimated from our data. The transition proceeds through a homogeneous nucleation mechanism ${ }^{12}$ at room temperature. At higher temperatures, the transformation occurs rapidly and yields the formation of larger $(1 \times 1)$ patches that are anisotropic in shape: long in the [110] direction and short in the [001]. The area of $(1 \times 1)$ patches increases fairly steeply with increasing $\theta_{\mathrm{co}}$ above the critical value.

Our LEED results are consistent with those summarized above. The transformation between both structures is controlled by $\mathrm{CO}$ and not by oxygen even when the surface is covered by the coadlayer. In conclusion, the surface is merely in the $(1 \times 2)$ structure below $\theta_{\mathrm{CO}} \approx 0.4$, and above this coverage it is in a mixture of $(1 \times 2)$ and $(1 \times 1)$ structures during $\mathrm{CO}_{2}$ formation.

\section{B. Reactivity of coadlayer}

Several $\mathrm{CO}_{2}$ formation peaks were reported on $\operatorname{Pd}(111),{ }^{2,3} \operatorname{Pd}(100),{ }^{33} \operatorname{Pd}(110),{ }^{7}$ and $\mathrm{Rh}(111)^{24}$ during heating the surface covered with $\mathrm{CO}$ and oxygen. The formation is extended to lower temperatures with increasing $\mathrm{CO}$ coverages. The reactivity of the coadlayer is enhanced by increasing the density of $\mathrm{CO}$ admolecules around oxygen adatoms. The results on $\mathrm{Pt}(110)(1 \times 2)$ shown in Fig. 1(a) are quite similar to those on the above surfaces, although the structure of the coadlayer is not clear at present. The appearance of several $\mathrm{CO}_{2}$ peaks on the present surface may be due to the density of adsorbates rather than the structure of the metal surface. For example, the $P_{2}-\mathrm{CO}_{2}$ formation was observed on both $(1 \times 1)$ and $(1 \times 2)$ patches as discussed below.

\section{Location of reaction site}

Carbon dioxide is produced from the reaction of adsorbed $\mathrm{CO}$ with oxygen adatoms. $\mathrm{CO}$ is mobile compared with oxygen. It is likely that $\mathrm{CO}$ diffuses to oxygen and reacts with it. The reaction site is on each oxygen adatom.
For the consideration of the spatial distribution of the product desorption, this reaction site should be positioned, since the product molecule is repulsed by the surface immediately prior to the desorption as discussed below and the shape of the repulsive potential, which is determined by the structure of the reaction site, is preserved in the spatial distribution. ${ }^{7}$

A few papers discussed the location of oxygen atoms on $\operatorname{Pt}(110)(1 \times 2)$. Ducros and Merrill proposed oxygen atoms in the valley from a streaky $(1 \times 2)$ LEED pattern. ${ }^{32}$ This was not confirmed in recent work, ${ }^{21,25}$ nor in the present work. Fusy et al, discussed the location of oxygen adsorbed at $97 \mathrm{~K}$ by using photoemission from adsorbed xenon. ${ }^{19} \mathrm{Our}$ recent experiments indicated that oxygen adsorbs merely in the molecular form below $160 \mathrm{~K}$ on this surface. ${ }^{20}$

We expect two possible adsorption sites for oxygen adatoms on the reconstructed surface, a three-fold hollow site on the declining terrace of a (111) structure, and a long bridge site in the valley. The valley has a structure quite similar to that on the nonreconstructed fcc(110) surface. Oxygen atoms have been proposed to be located on a long bridge site in the valley on $\mathrm{Ag}(110),{ }^{34,35} \mathrm{Cu}(110),{ }^{36}$ and $\operatorname{Pd}(110)^{37}$ surfaces.

The former site has been concluded on $\operatorname{Pt}(111)$, where oxygen adatoms form a $p(2 \times 2)$ overlayer structure. ${ }^{38}$ The recent studies with the transmission channeling technique have shown that oxygen atoms are adsorbed in the fcc threefold hollow site (without a second-layer host atom directly below) exclusively at a height of $0.85 \pm 0.06 \AA$ above the $\mathrm{Pt}$ surface layer. ${ }^{39}$ These two adsorption sites may play as the reaction site for the $\mathrm{CO}_{2}$ formation on the reconstructed surface. On the other hand, on the $(1 \times 1)$ surface, a long bridge site is expected to be a reaction site.

\section{Overview of desorption model}

The desorption of $\mathrm{CO}_{2}$ from the physisorption state on platinum metals is complete below $130 \mathrm{~K} .^{40}$ The desorption shows a simple cosine distribution. ${ }^{41,42}$ In this case, no excess translational energy is expected compared with the surface temperature. ${ }^{43}$

On the other hand, the sharp angular distribution of the desorption of product $\mathrm{CO}_{2}$ suggests that the molecules leave the surface with an excess translational energy. In fact, the excess energy has been observed in the normal velocity component of $\mathrm{CO}_{2}$ produced on $\mathrm{Pt}(111)^{44}$ and $\mathrm{Rh}(111)$ surfaces. ${ }^{45}$ The desorption flux of $\mathrm{CO}_{2}$ in both cases is sharply collimated along the surface normal. ${ }^{16,24,46-48} \mathrm{The}^{\mathrm{CO}_{2}}$ molecules are desorbed immediately after the formation without being trapped in the physisorption state. The excess energy would be dissipated if it is trapped.

This excess translational energy originates from a repulsive force operative between surfaces and nascent molecules. The molecule in the physisorption is generally located further from the surface than the dissociated fragments in the chemisorption. Thus, the surface is likely to exert a repulsive force on molecules being produced associatively. The detailed discussion has previously been given on $\operatorname{Pd}(111)$ and $\operatorname{Pd}(110){ }^{3,7}$ Along this line, a one-dimensional activation barrier model has been proposed by Comsa ${ }^{49}$ and van Willigen. ${ }^{50}$ In this model, the translational energy is predict- 
ed to increase sharply with the increasing desorption angle. Furthermore, no crystal azimuth dependence is predicted in the desorption flux.

In the experiments reported so far, however, this energy decreases or remains fairly constant for the desorption of hydrogen from $\mathrm{Ni}(111), \mathrm{Ni}$ (poly), ${ }^{51-53} \mathrm{Cu}(100)$ and $\mathrm{Cu}(111) .{ }^{54}$ A similar decrease of the translational energy has been reported for the desorption of $\mathrm{CO}_{2}$ produced on $\mathrm{Pt}(111)^{44}$ and $\mathrm{Rh}(111) .^{45}$ In particular, the translational temperature of $\mathrm{H}_{2}$ from $\mathrm{Ni}$ (111) goes below the surface temperature above about $\theta=65^{\circ}$. 55 No classical theory can explain this slow desorption. Toya et al. have succeeded in modifying the above classical one-dimensional model by introducing the quantum effect. ${ }^{56}$ The new theory would predict the anisotropy in the desorption flux, which was actually observed for the desorption of $\mathrm{CO}_{2}$ produced on $\mathrm{Pd}(110)$ surfaces. ${ }^{7}$ However, it is still difficult to detect azimuth dependence on flat surfaces such as $\operatorname{Pd}(111)$ surfaces. $^{57}$

\section{E. Spatial distribution of $\mathrm{CO}_{2}$ desorption}

With the $\mathrm{CO}$ oxidation, the reaction and product desorption occur on each oxygen adsorption site. The reconstructed surface of $\mathrm{Pt}(110)$ has two possible reaction sites, a three-fold hollow site on the declining terrace and a long bridge site in the valley, as shown in Fig. 5. The two-directional desorption is expected when the reactive desorption of $\mathrm{CO}_{2}$ takes place on the former. The $\mathrm{CO}_{2}$ desorption is collimated along the surface normal on all surfaces reported so far, i.e., $\operatorname{Pt}(111),{ }^{42,46-48} \operatorname{Pd}(111),{ }^{3} \operatorname{Pd}(110),{ }^{7} \operatorname{Rh}(111),{ }^{24}$ and $\operatorname{Ir}$ (poly).$^{58}$ On the other hand, the angular distribution should be similar to that on $\operatorname{Pd}(110)$ when the reaction occurs in the valley, since the site has the local structure quite similar to that on the nonreconstructed $\operatorname{Pd}(110)$. The desorption may show a sharp angular distribution perpendicular to the valley and a broader one along it. ${ }^{7}$

The two-directional desorption was actually observed for $P_{1}$ - and $P_{2}-\mathrm{CO}_{2}$ when the initial $\mathrm{CO}$ coverage was small. The desorption of $P_{2}-\mathrm{CO}_{2}$ is collimated at \pm 23 degrees off the bulk surface normal in the [001] direction, and for $P_{1^{-}}$ $\mathrm{CO}_{2}$ at \pm 21 degrees. It is concluded that the reactive desorption takes place on the terrace. These angles, however, are significantly less than the declining angle of terraces without adsorbates $\left( \pm 30\right.$ degrees $\left.^{8-10}\right)$.

Two factors may be considered for this small collimation angle. The first is the contribution from $(1 \times 1)$ patches. When the surface has significant $(1 \times 1)$ patches and the desorption of $\mathrm{CO}_{2}$ takes place on this region as well, the angular distribution in the [001] direction will behave as if the collimation angle in the two-directional desorption would decrease. The desorption from $(1 \times 1)$ patches would contribute mostly to the signal around the surface normal as discussed below. The deconvolution of the resultant distribution will underestimate the angle of the collimation.

The second factor has already been discussed for the hydrogen desorption from a stepped $\mathrm{Cu}(310)$ surface by Balooch et al $;{ }^{14}$ the repulsive potential operative to desorbing molecules will lose the effect from the surface corrugations in the presence of the smoothing effect by metal electrons when the position of product formation is far from the surface. This effect will reduce the collimation angle.

When the surface consists of a mixture of $(1 \times 1)$ and $(1 \times 2)$ structures, the angular distribution in the [001] direction consists of three components. The first two are the contribution from the two-directional desorption from $(1 \times 2)$ patches. The other is the desorption from the $(1 \times 1)$ region. We deconvoluted the angular distribution curve of $P_{2}-\mathrm{CO}_{2}$ generated from a high $\mathrm{CO}$ coverage in the [001] direction. Typical results are shown as the dotted and dashed curves in Fig. 6. In these procedures, the contribution of the two-directional desorption was first assumed as the $\cos (\theta \pm 23)^{13}$ form and then fitted with the data. The contribution from $(1 \times 1)$ was derived as the difference between observed signals and the two-directional components. The results are shown by the dashed curve. It is collimated sharply along the bulk surface normal, as $(\cos \theta)^{20-25}$. The resultant component has an anisotropic angular distribution, i.e., it is sharp in the [001] direction and broad in the [1 $1 \overline{1} 0]$ direction. This agrees well with that on $\operatorname{Pd}(110)(1 \times 1)$ surfaces. It should be noticed here that a small contribution from the $(1 \times 1)$ region obscures the observation of the two-directional desorption.

The desorption flux of $P_{3}$ - and $P_{4}-\mathrm{CO}_{2}$ is also expected to involve the contribution from the $(1 \times 1)$ and $(1 \times 2)$ surfaces, because those are formed below $250 \mathrm{~K}$ and at high CO coverages. This seems to be a reason why the angular distribution in the [001] direction is broader than that in the [110] direction. In our model proposed in the previous paper, ${ }^{7}$ the former distribution is always sharper than the other when the reactive desorption takes place on a long bridge site in the valley on the fcc (110) nonreconstructed surface.

Each component in the two-directional desorption has a very sharp angular distribution of $(\cos \theta)^{13 \pm 2}$. This is not unexpected, since the distribution of $\mathrm{CO}_{2}$ produced on bulk $\mathrm{Pt}$ (111) surfaces was reported as $(\cos \theta)^{8-10}$ form. ${ }^{42}$

Finally, we consider the lack of the reactive desorption in the valley on the reconstructed plane. The thorough desorption of $\mathrm{CO}_{2}$ in the two-dimensional form does not necessarily mean the absence of oxygen in the valley. It is still consistent with the fact that oxygen is located in the valley and less reactive towards $\mathrm{CO}$. According to careful analysis of work function change, LEED patterns and XPS data, CO has been suggested to occupy on-top sites on [110] atomic row at small $\mathrm{CO}$ coverages. ${ }^{17}$ These $\mathrm{CO}$ molecules may be more reactive to oxygen on the terrace than that in the valley.

\section{SUMMARY}

The oxidation of carbon monoxide was studied on $\operatorname{Pt}(110)(1 \times 2)$ reconstructed surfaces by angle-resolved thermal desorption and low-energy electron diffraction. The results are summarized as follows:

(1) The heating of a coadlayer of $\mathrm{CO}$ and oxygen produces carbon dioxide in the temperature range of $120 \mathrm{~K} \sim 450 \mathrm{~K}$. (2) The $\mathrm{CO}_{2}$ formation extends to lower temperatures with increasing $\mathrm{CO}$ coverages, yielding four peaks, $\boldsymbol{P}_{1^{-}}$around $400 \mathrm{~K}, P_{2^{-}}(300 \mathrm{~K}), P_{3^{-}}(250 \mathrm{~K})$ and $P_{4^{-}}-\mathrm{CO}_{2}$ peaks $(170 \mathrm{~K})$. (3) The desorption of $\mathrm{CO}_{2}$ in each peak shows a similar and sharp angular distribution collimated along the bulk surface 
normal in the [110] direction (along the surface trough). (4) In the [001] direction (perpendicular to the surface trough ), $P_{1}$ - and $P_{2}-\mathrm{CO}_{2}$ desorb in the two-directional form, when the initial CO coverage is small.

(5) The desorption of $P_{3}-$ and $P_{4}-\mathrm{CO}_{2}$, and also $P_{2}-\mathrm{CO}_{2}$ is collimated along the bulk surface normal even in the [001] direction, when the initial $\mathrm{CO}$ coverage is high. Under these conditions, the partial removal of the reconstruction was confirmed by LEED observations.

\section{ACKNOWLEDGMENT}

This work was supported in part by a Grant-in-Aid for General Scientific Research from the Ministry of Education, No. 62540274 .

${ }^{1}$ (a) W. Witt and E. Bauer, Ber. Bunsenges, Phys.Chem. 90, 248 (1986); (b) H. Pfnür and H. J. Heier, ibid. 90, 272; (c) T. Trigides, P. K. Wu, W. Moritz, and M. G. Lagally, ibid. 90, 277; K. Christmann, ibid. 90, 307. ${ }^{2}$ H. Conrad, G. Ertl, and J. Küppers, Surf. Sci. 76, 323 (1978).

${ }^{3}$ T. Matsushima and H. Asada, J. Chem. Phys. 85, 1658 (1986).

${ }^{4}$ R. J. Behm, P. A. Thiel, P. R. Norton, and P. E. Bindner, Surf. Sci. 147, 143 (1984).

${ }^{5}$ (a) R. Imbihl, M. P. Cox, and G. Ertl, J. Chem. Phys. 64, 3519 (1986);

(b) P. Möller, K. Wetzel, M. Eiswirth, and G. Ertl, J. Chem. Phys. 85, 5328 (1986).

${ }^{6}$ For example, G. A. Somorjai, Chemistry in Two Dimensions: Surfaces (Cornell University, Ithaca and London), p. 479.

${ }^{7}$ T. Matsushima, J. Chem. Phys. 91,5722 (1989).

${ }^{8}$ (a) D. L. Adams, H. B. Nielsen, M. A. van Hove, and A. Ignatiev, Surf. Sci. 104, 47 (1981); (b) E. C. Sowa, M. A. Van Hove, and D. L. Adams, Surf. Sci. 199, 174 (1988).

${ }^{9} \mathrm{H}$. Niehus, Surf. Sci. 145, 407 (1984).

${ }^{10}$ T. E. Jackman, J. A. Davis, D. P. Jackson, W. E. Unertl, and P. R. Norton, Surf. Sci. 120, 389 (1982).

"Q. Gao and T. T. Tsong, Phys. Rev. Lett. 57, 452 (1986).

${ }^{12}$ T. Gritsch, D. Coulman, R. J. Behm, and G. Ertl, Appl. Phys. A, 49, 403 (1989); T. Gritsch, D. Coulman, R. J. Behm, and G. Ertl, Phys. Rev. Lett. 63, 1086 (1989).

${ }^{13}$ E. Kirsten and K. H. Rieder, Surf. Sci. 222, L837 (1989).

${ }^{14}$ M. Balooch, M. J. Cardillo, D. R. Miller, and R. E. Stickney, Surf. Sci. 46, 358 (1974)

${ }^{15}$ K. D. Rendulic, Appl. Phys. A 47, 55 (1988).

${ }^{16} \mathrm{~T}$. Matsushima, Surf. Sci. 127, 403 (1983).

${ }^{17}$ N. Freyer, M. Kiskinova, G. Pirug, and H. P. Bonzel, Appl. Phys. A 39 209 (1986)

${ }^{18}$ P. Hofmann, S. R. Bare, and D. A. King, Surf. Sci. 117, 245 (1982).

19J. Fusy and R. Ducros, Surf. Sci. 214, 337 (1987).
${ }^{20} \mathrm{Y}$. Ohno and T. Matsushima, (unpublished data).

${ }^{21}$ N. Freyer, M. Kiskinova, G. Pirug, and H. P. Bonzel, Surf. Sci. 166, 206 (1986).

${ }^{22}$ T. Matsushima, Surf. Sci. 217, 155 (1989).

${ }^{23}$ T. Matsushima and Y. Ohno, Chem. Phys. Lett. (in press).

${ }^{24}$ T. Matsushima, T. Matsui, and M. Hashimoto, J. Chem. Phys. 81, 5151 (1984).

${ }^{25}$ S. Ferrer and H. P. Bonzel, Surf. Sci. 119, 243 91982)

${ }^{26}$ G. L. Kellogg, Phys. Rev. Lett. 55, 2168 (1985).

${ }^{27} \mathrm{Q}$. Gao and T. T. Tsong, Phys. Rev. Lett. 57, 4452 (1986).

${ }^{28}$ K. Heinz, A. Barthel, L. Hammer, and K. Müller, Surf. Sci. 191, 174 (1987).

${ }^{29}$ R. Imbihl, S. Ladas, and G. Ertl, Surf. Sci. 206, L903 (1988).

${ }^{30}$ B. E. Hayden, A. W. Robinson, and P. M. Tucker, Surf. Sci. 192, 163 (1987).

${ }^{3}$ 'S. Ferrer and H. P. Bonzel, Surf. Sci. 119, 234 (1982).

${ }^{32}$ R. Ducros and R. P. Merrill, Surf. Sci. 55, 227 (1976).

${ }^{33}$ E. M. Stuve, R. J. Madix, and C. R. Brundle, Surf. Sci. 146, 155 (1984).

${ }^{34}$ W. Heiland, F. Eberl, and E. Taglauer, Surf. Sci. 53, 383 (1975).

${ }^{35}$ C. Backs, C. P. M. de Groot, and P. Biloen, Surf. Sci. 104, 300 (1981).

${ }^{36}$ J. F. Wendelken, Surf. Sci. 30, 525 (1972).

${ }^{37}$ M. Nishijima, M. Jo, Y. Kuwahara, and M. Onchi, Solid State Commun. 60, 257 (1986).

${ }^{38}$ P. R. Norton, J. A. Davies, and T. E. Jackman, Surf. Sci. 122, L593 (1982).

${ }^{39} \mathrm{~K}$. Mortensen, C. Klink, F. Jensen, F. Besenbacher, and I. Stensgaard, Surf. Sci. 220, L701 (1989).

${ }^{40}$ P. R. Norton, Surf. Sci. 44, 624 (1974).

${ }^{41}$ T. Matsushima, J. Catal. 83, 446 (1983).

${ }^{42}$ T. Matsushima, Surf. Sci. 127, 403 (1983).

${ }^{43}$ J. E. Hurst, C. A. Becker, J. P. Cowin, K. C. Jands, L. Wharton, and D. J. Auerbach, Phys. Rev. Lett. 43, 1175 (1979).

${ }^{44}$ C. A. Becker, J. P. Cowin, L. Wharton, and D. J. Auerbach, J.Chem. Phys. 67, 3394 (1977); C. A. Becker, Ph.D. thesis, University of Chicago (1979) (unpublished).

${ }^{45}$ L. S. Brown and S. J. Sibener, J. Chem. Phys. 90, 2807 (1989).

${ }^{46}$ R. L. Palmer and J. N. Smith, J. Chem. Phys. 60, 1453 (1974).

${ }^{47}$ C. T. Campbell, G. Ert1, H. Küppers, and J. Segner, J. Chem. Phys. 73 5862 (1980).

${ }^{48}$ J. Segner, C. T. Campbell, G. Doyen, and G. Ertl, Surf. Sci. 138, 505 (1984).

${ }^{49} \mathrm{G}$. Comsa, J. Chem. Phys. 48, 3235 (1968).

${ }^{50}$ W. Van Willigen, Phys. Lett. A 28,80 (1968).

${ }^{51}$ A. E. Dabiri, T. J. Lee, and R. E. Stickney, Surf. Sci. 26, 522 (1971).

${ }^{52}$ G. Comsa, R. David, and V. D. Rendulic, Phys. Rev. Lett. 38, 775 (1977); G. Comsa and R. David, Chem. Phys. Lett. 49, 512 (1977).

${ }^{53}$ G. Comsa, R. David, and B. J. Schumacher, Surf. Sci. 85, 45 (1979).

${ }^{54} \mathrm{G}$. Comsa and R. David, Surf. Sci. 117, 77 (1982).

${ }^{55} \mathrm{G}$. Comsa and R. David, Surf. Sci. Rep. 5, 145 (1985).

${ }^{56}$ Y. Ohno, T. Toya, S. Ishi, and K. Nagai, Appl. Surf. Sci. 33/34, 238, (1988).

${ }^{57}$ T. Matsushima, Vacuum, (in press).

${ }^{58}$ T. Matsushima, J. Phys. Chem. 88, 202 (1984). 
The Journal of Chemical Physics is copyrighted by the American Institute of Physics (AIP). Redistribution of journal material is subject to the AIP online journal license and/or AIP copyright. For more information, see http:/ojps.aip.org/jcpo/jcpcr/jsp Copyright of Journal of Chemical Physics is the property of American Institute of Physics and its content may not be copied or emailed to multiple sites or posted to a listserv without the copyright holder's express written permission. However, users may print, download, or email articles for individual use. 